\title{
O CONTRATO DE RESERVA DE MARGEM CONSIGNÁVEL NA JURISPRUDÊNCIA CATARINENSE
}

\section{CONSIGNABLE MARGIN RESERVE CONTRACT IN THE STATE OF SANTA CATARINA'S JURISPRUDENCE}

\section{Leandro Ernani Freitag ${ }^{1}$}

Resumo: O presente trabalho trata sobre o tema do contrato de reserva de margem consignável e sua recepção na jurisprudência catarinense. Primeiramente, é analisada a aplicabilidade do Código de Defesa do Consumidor às instituições financeiras, e quais as principais consequências de tal incidência, notadamente ante o caráter protetivo da legislação consumerista como expressão da eficácia diagonal dos direitos fundamentais, e em especial no que pertine à inversão do ônus da prova. Apresentam-se os conceitos de empréstimo consignado e de reserva de margem consignável, diferenciando-os com a indicação da lei e de regulamento aplicável a esta última modalidade. Com isso, objetiva-se situar o tema e possibilitar a compreensão sobre as possíveis irregularidades atinentes à mencionada espécie contratual, com ênfase nos principais vícios que são comumente arguidos pelos contratantes em ações judiciais que debatem acerca da reserva de margem consignável. Após, analisam-se julgados sobre o contrato em questão, no âmbito das Turmas Recursais de Santa Catarina e do Tribunal de Justiça catarinense, separadamente, com o intuito de apresentar os atuais entendimentos dominantes em tais órgãos, sobre sua higidez e validade, ou abusividade e, neste último caso, quais as consequências determinadas pelo órgão julgador decorrentes do reconhecimento da nulidade da avença, bem

1. Juiz de Direito da Vara Única da Comarca de Catanduvas/SC. Especialista em: Direito Constitucional (Uniderp); Direito Público e Privado: Material e Processual (Unoesc/Esmesc); Direito Penal e Processual Penal (UGF); Direito Civil (UGF); Direito Administrativo (UGF); Direito Tributário (AVM); Direito Processual Civil (Unyleya); Direito e Gestão Judiciária (Academia Judicial/TJSC). E-mail: lefreitag@tjsc.jus.br. 
como quais os fundamentos utilizados pelos julgadores como razão de decidir.

Palavras-chave: Contrato bancário. Reserva de margem consignável. Legalidade. Abusividade.

Abstract: The present work deals with the topic of the consignable margin reserve contract, and its reception in the jurisprudence of Santa Catarina. Firstly, it is analyzed the applicability of the Consumer Protection Code to financial institutions, and which are the main consequences of such incidence notably in view of the protective nature of consumer legislation as an expression of the diagonal effectiveness of fundamental rights, and in particular regarding the inversion of the burden of proof. There are presented the concepts of consignable loan and of consignable margin reserve, differentiating them, with the indication of the law and regulation applicable to the latter modality. With that, it is aimed to situate the topic and make possible the comprehension about the possible irregularities regarding the aforementioned contractual species, with an emphasis on the main flaws that are commonly alleged by contracting parties in lawsuits that discuss the consignable margin reserve. After that, judgments are analyzed on the contract in question, within the scope of the Santa Catarina Appeals Panels and the Santa Catarina Court of Justice, separately, with the goal of presenting the current prevailing understandings in such bodies, about its veracity and validity, or abusiveness; and, in the latter case, which are the consequences determined by the judging body arising from the recognition of the nullity of the agreement, as well as what are the grounds used by the judges as a reason to decide.

Keywords: Bank contract. Consignable margin reserve. Legality. Abusiveness.

\section{INTRODUÇÃO}

O presente estudo destina-se a analisar a atual visão da jurisprudência catarinense acerca da validade do contrato de reserva de margem consignável (RMC). A pesquisa se justifica pela existência de um alto número de ações judiciais questionando a validade do contrato, sob a alegação da ocorrência de diversos vícios contratuais - ocasionando, 
em um expressivo número de casos, não somente a nulidade do pacto e o retorno das partes ao estado anterior, mas também a condenação da instituição financeira ao pagamento de indenização por danos morais, bem como repetição em dobro do valor por ela anteriormente cobrado.

Assim, o estudo ora apresentado procura responder às seguintes indagações: é válido o contrato de reserva de margem consignável? Em caso negativo, que condições são determinantes para o reconhecimento de sua nulidade e quais as consequências que resultam desse entendimento?

Para os fins do presente texto, inicialmente, analisam-se as principais características do Código de Defesa do Consumidor (CDC) no sistema jurídico pátrio, e sua aplicabilidade às instituições financeiras, inclusive quanto à inversão do ônus probatório, circunstância que pode impactar diretamente no resultado das ações judiciais sobre o contrato em deslinde.

O capítulo seguinte destina-se ao exame das espécies contratuais de empréstimo consignado e reserva de margem consignável para estabelecer suas diferenças e semelhanças, bem como à indicação da legislação que rege tal modalidade contratual.

Na sequência, são estudados os vícios que geralmente são alegados pelos contratantes ao judicialmente pleitearem a nulidade do contrato como erro, dolo, onerosidade excessiva, falta de informações adequadas e ausência de plena compreensão do teor do contrato pelo consumidor.

Por fim, é feito um apanhado dos julgados das Turmas Recursais e do Tribunal de Justiça de Santa Catarina que versam sobre o contrato de reserva de margem consignável, verificando-se a presença de decisões em sentido antagônico e analisando-se as bases de suas fundamentações.

A pesquisa far-se-á pela forma qualitativa, utilizando-se análise e interpretação de dados e de fontes bibliográficas, além de pesquisa jurisprudencial, com o objetivo de compreender a questão posta e apresentar uma solução para o problema. O método pelo qual se desenvolve a pesquisa é o dialético, de modo que são expostas e debatidas as argu- 
mentações e contra-argumentações a respeito da questão, a fim de se atingir uma síntese do assunto.

\section{O CÓDIGO DE DEFESA DO CONSUMIDOR E AS INSTITUIÇÕES FINANCEIRAS}

O Código de Defesa do Consumidor (Lei n. 8.078/1990), editado em cumprimento a mandamento constitucional (art. $5^{\circ}$, XXXII, e art. 170, V, da Constituição Federal de 1988, e art. 48 de suas Disposições Transitórias), enfeixa uma série de dispositivos de índole protetiva ao consumidor, o qual é compreendido como parte mais vulnerável na relação consumerista, a merecer especial proteção do ordenamento jurídico.

Assim, por exemplo, o direito à informação adequada e clara (art. $6^{\circ}$, III), a proteção contra publicidade enganosa e abusiva (art. $6^{\circ}, \mathrm{IV}$ ), a possibilidade de inversão do ônus da prova (art. $6^{\circ}$, VIII; art. $12, \S$ $3^{\circ}$; art. $14, \S 3^{\circ}$; art. 38), a proibição de cláusulas abusivas (art. 51), a viabilidade de tutela jurisdicional individual ou coletiva (art. 81), entre outros, são marcas características do sistema consumerista, que demonstram a preocupação do legislador atinente à efetiva proteção e ao amparo do consumidor.

Tais expressões demonstram o que parte da doutrina denomina de eficácia diagonal dos direitos fundamentais: além da eficácia vertical (aplicável nas relações entre Estado e cidadão) e da eficácia horizontal (incidente nos relacionamentos entre particulares), a eficácia diagonal implica existência de relações entre particulares, marcada pela peculiaridade de existência de um desnível de forças, uma acentuada vulnerabilidade de uma das partes pela subordinação ou desigualdade de poder, típicas, exempli gratia, das relações de consumo e laborais (PRAZERES, 2019, p. 226). Nessa tessitura, não é apenas natural, mas necessário que o sistema jurídico ofereça meios protetivos da parte mais débil, com o desiderato de equilibrar a relação travada e possibilitar a solução de eventuais imbróglios da forma mais adequada possível.

Após o CDC entrar em vigor, as instituições tentaram subtrair as relações travadas com seus clientes do âmbito de sua aplicação - tese que 
há muito foi rejeitada, entendendo-se pela aplicabilidade do diploma consumerista, seja pela literalidade do art. $3^{\circ}, \S 2^{\circ}$, do CDC, que expressamente menciona serviços de natureza bancária, seja porque o Código, norma de ordem pública e natureza cogente, aplica-se a todas as relações de consumo, "[...] mesmo quando a atividade tenha legislação específica, como ocorre com a incorporação, o parcelamento do solo, o contrato bancário, pois em todas elas, guardadas as peculiaridades de cada caso, incidem os princípios do CDC sobre abusividade, boa-fé, direito de informação etc". (STJ, REsp 106.888/PR, Rel. Ministro Cesar Asfor Rocha, Segunda Seção, j. em 28/3/2001, DJ 5/8/2002, p. 196). O entendimento culminou com a edição do enunciado 297 da Súmula do Superior Tribunal de Justiça, verbatim: "O Código de Defesa do Consumidor é aplicável às instituições financeiras", de modo a pacificar a questão em definitivo.

Consequentemente, às avenças de natureza bancária, tem incidência o específico regime protetivo ao consumidor, merecendo destaque, em meio a várias outras, no concernente à espécie contratual analisada no presente texto, além da já mencionada inversão do ônus probatório, as disposições sobre: interpretação contratual mais favorável ao consumidor (art. 47, CDC); forma do contrato de adesão (art. 54, CDC); vedação de aproveitamento da fraqueza ou ignorância do consumidor, conforme sua idade, saúde, conhecimento ou condição social, para impingir-lhe seus produtos ou serviços, e de exigência de vantagem manifestamente excessiva (art. 39, IV e V, do CDC).

Não obstante, a inversão do ônus da prova com base no diploma consumerista não exime o consumidor de comprovar os fatos constitutivos do direito invocado ou, ao menos, início de prova apta a roborar suas alegações - inclusive para evitar a transferência ao fornecedor de ônus intransponível, id est, de prova impossível de ser por ele produzida. Nessa trilha: "Ainda que haja a inversão do ônus da prova em decorrência da hipossuficiência do consumidor, isso não exime o autor de trazer aos autos provas dos fatos constitutivos de seu direito ou, ao menos, inícios de prova para comprovar suas alegações" (TJSC, Apelação 
Cível n. 0016929-87.2011.8.24.0064, de São José. Rel. Des. Fernando Carioni, Terceira Câmara de Direito Civil, j. 5-11-2019).

De outra mão, tem-se entendido que, se o banco alega que os descontos foram efetuados em função de contrato regularmente pactuado, a ele incumbe comprovar sua alegação, exibindo o instrumento contratual respectivo - o que, de fato, independe da inversão do ônus probatório e decorre da aplicação da regra geral prevista no art. 373, II, do CPC, pois, de acordo com a regra geral, quem faz uma afirmação deve prová-la; conforme tradicional parêmia, "alegar e não provar é o mesmo que não alegar" (allegarenihil et allegatum non probare paria sunt). Não o fazendo, não terá se desincumbindo do ônus, que conforme a lei lhe cabia, de comprovar a existência de fato impeditivo do alegado direito do autor.

\section{EMPRÉSTIMO CONSIGNADO E RESERVA DE MARGEM CONSIGNÁVEL}

O empréstimo consignado consiste na possibilidade de o interessado adquirir financiamento em instituição financeira, a ser quitado por meio de desconto do respectivo valor das parcelas diretamente pelo empregador - ou pelo órgão previdenciário, no caso dos aposentados e pensionistas. O desconto, nessa sistemática, é efetuado no momento do recebimento da verba salarial ou do benefício previdenciário, implicando, na prática, na sua retenção, de modo a inviabilizar que o consumidor tenha acesso ao valor da parcela.

Há vantagens para o consumidor e para a instituição financeira: para esta, a atenuação do risco de inadimplência, já que o valor da parcela, como dito, já é descontado quando o cliente aufere sua verba salarial ou previdenciária; para aquele, quanto aos juros, que costumam ser consideravelmente menores que os praticados em mútuos que não seguem tal modalidade, o que se justifica pela citada minimização da possibilidade de inadimplência (POMODORO, 2019, p. 12). Além disso, ambos (banco e cliente) já sabem, na contratação, qual o valor disponibilizado e o número fixo de parcelas. 
Já a reserva de margem consignável nada mais é que o limite reservado no valor da renda mensal do benefício, destinado exclusivamente para uso no cartão de crédito. Nessa modalidade, o crédito é limitado e emprestado para pagamento da fatura mensal do cartão, com os gastos que se acumulam mensalmente pelo uso; ao final do período mensal, é descontado do contracheque do contratante ou de seu benefício previdenciário tão somente a parcela mínima para pagamento. Ou seja, o valor restante, que não é descontado, deve ser pago pelo cliente, por meio da fatura que é enviada à sua residência ou disponibilizada em portal eletrônico da instituição financeira.

A forma em questão torna inviável conhecer previamente o valor financiado e o número de parcelas no momento da pactuação, o que depende de ação futura do consumidor, a variar, pois, conforme o uso do cartão e o pagamento das faturas mensais. Assim, o banco tem a certeza apenas do pagamento da parcela mínima, razão pela qual os encargos são maiores do que aqueles praticados no empréstimo consignado.

As modalidades foram alvo de diversas alterações legislativas ao longo do tempo (inclusive por medidas provisórias). Dispõe a Lei n. 10.820/2003, quantos aos aposentados e pensionistas:

Art. $6^{\circ}$ Os titulares de benefícios de aposentadoria e pensão do Regime Geral de Previdência Social poderão autorizar o Instituto Nacional do Seguro Social - INSS a proceder aos descontos referidos no art. $1^{\circ}$ e autorizar, de forma irrevogável e irretratável, que a instituição financeira na qual recebam seus benefícios retenha, para fins de amortização, valores referentes ao pagamento mensal de empréstimos, financiamentos, cartões de crédito e operações de arrendamento mercantil por ela concedidos, quando previstos em contrato, nas condições estabelecidas em regulamento, observadas as normas editadas pelo INSS. [...]

$\S 5^{\circ}$ Os descontos e as retenções mencionados no caput não poderão ultrapassar o limite de $35 \%$ (trinta e cinco por cento) do valor dos benefícios, sendo $5 \%$ (cinco por cento) destinados exclusivamente para:

I - a amortização de despesas contraídas por meio de cartão de crédito; ou 
II - a utilização com a finalidade de saque por meio do cartão de crédito (BRASIL, 2003).

Idêntica trilha segue o regulamento (Instrução Normativa INSS n. $28 / 2008$ ), cujo art. $3^{\circ}$ prevê que, no momento da contratação, os descontos não poderão exceder ao limite de $35 \%$ do valor da renda mensal do benefício, sendo $30 \%$ para operações de empréstimo pessoal e 5\% para operações de cartão de crédito.

Tais dispositivos, contudo, têm eficácia suspensa temporariamente; nos termos do determinado pela Lei n. 14.131/2021, convertida da Medida Provisória n. 1.006/2020, até 31 de dezembro de 2021, o percentual máximo de consignação será de $40 \%$ (quarenta por cento), dos quais 5\% (cinco por cento) ficam reservados exclusivamente para amortização de despesas contraídas por meio de cartão de crédito ou utilização com finalidade de saque por meio do cartão de crédito. A Instrução Normativa INSS n. 14/2021 regulamenta, na mesma senda. Tal aumento "moderado e temporário" do limite do crédito "[...] representa opção mais vantajosa para lidar com a contração no mercado de crédito por ser a que representa menores riscos para as instituições financeiras e a que menos onera os beneficiários do Regime Geral de Previdência Social - RGPS" (BRASIL, 2020) e, conforme constou na ementa da mencionada medida provisória, fundamenta-se nos impactos econômicos advindos da pandemia da Covid-19.

\section{RMC E VÍCIOS CONTRATUAIS}

Geralmente, em ações judiciais que discutem sobre o contrato de RMC, o consumidor não impugna a veracidade do pacto ou sua assinatura nele aposta. A insurgência se volta contra o conteúdo - no mais das vezes argumentando existência de vícios como dolo, erro, informação inadequada, abusividade e venda casada.

Sobre o primeiro, ensina a doutrina que "dolo é o artifício ou expediente astucioso, empregado para induzir alguém à prática de um ato que o prejudica, e aproveita ao autor do dolo ou a terceiro. Consiste em sugestões ou manobras maliciosamente levadas a efeito por uma parte, 
a fim de conseguir da outra uma emissão de vontade que lhe traga proveito, ou a terceiro" (GONÇALVES, 2018, p. 414-415). Aqui, há uma ação de um dos contratantes, para obter uma vantagem, em detrimento do outro contratante, ludibriado.

Já o erro "é um engano fático, uma falsa noção, em relação a uma pessoa, ao objeto do negócio ou a um direito, que acomete a vontade de uma das partes que celebrou o negócio jurídico" (TARTUCE, 2020, n.p.). A teor do art. 138 do Código Civil, o erro torna o negócio anulável, desde que o erro seja substancial, isto é, possa ser percebido por pessoa de diligência normal, em face das circunstâncias em que o negócio foi celebrado.

Quanto a esses dois vícios, muito embora frequentemente alegados, o reconhecimento é, entende-se, problemático, já que geralmente inexistem testemunhas que presenciaram o contrato sendo firmado, de sorte que apenas o consumidor e o preposto da instituição financeira é que tiveram ciência direta da pactuação quando de sua formação. Em virtude disso, há, a respeito, no mais das vezes, tão somente a alegação do contratante, tanto acerca do dolo do banco quanto do erro dele próprio - sendo mister recordar a alhures mencionada impossibilidade de inversão do ônus da prova em desfavor do fornecedor, quando resulta em ônus impossível de ser vencido (prova diabólica).

Nesse tema, comumente se alega a condição particular do consumidor, notadamente quanto à idade, condições psicológicas, necessidade financeira e pouca instrução, como fatores que seriam capazes de demonstrar tanto o ardil e o dolo por parte da financeira quanto o erro por parte do contratante. O problema, contudo, é que não há prova concreta do erro ou do dolo; sua existência, regra geral, deve ser aferida do conjunto de indícios e circunstâncias, o que impede o uso da mesma medida e de idêntica resposta para todos os casos postos a Juízo, tornando a análise necessariamente casuística.

De toda sorte, justamente para salvaguardar os direitos dos consumidores que buscam tal negócio jurídico é que o regulamento exige uma série de formalidades para a validade da avença. A respeito, dispõe a Instrução Normativa do Instituto Nacional do Seguro Social (INSS) n. 
28/2008, em seu art. $3^{\circ}$, III, que a autorização deve ser dada “[...] de forma expressa, por escrito ou por meio eletrônico e em caráter irrevogável e irretratável, não sendo aceita autorização dada por telefone e nem a gravação de voz reconhecida como meio de prova de ocorrência".

Ainda, tangenciando o ponto, para garantia do cumprimento do adequado dever de informação, prevê a mesma normativa, em seu art. 21, que é preciso dar ciência ao consumidor, no mínimo, dos seguintes elementos: valor total com e sem juros; taxa efetiva mensal e anual de juros; todos os acréscimos remuneratórios, moratórios e tributários que eventualmente incidam sobre o valor do crédito contratado; valor, número e periodicidade das prestações; soma total a pagar com o empréstimo pessoal ou o limite máximo previsto para cartão de crédito; data do início e fim do desconto; valor da comissão paga aos terceirizados contratados pelas instituições financeiras para a operacionalização da venda do crédito, quando não for efetuado por sua própria rede; o número do cadastro nacional de pessoas jurídicas (CNPJ) da agência bancária que realizou a contratação quando realizado na própria rede, ou CNPJ do correspondente bancário e o número do cadastro de pessoas físicas (CPF) do agente subcontratado pelo anterior, acrescido de endereço e telefone.

Além disso, a atual redação da normativa citada, no dispositivo subsequente, exige que o contrato seja acompanhado de "termo de consentimento esclarecido". In verbis:

Art. 21-A. Sem prejuízo das informações do art. 21, nas autorizações de descontos decorrentes da celebração de contratos de Cartão de Crédito com Reserva de Margem Consignável, o contrato firmado entre o beneficiário do INSS e a instituição consignatária deverá, obrigatoriamente, nos termos da decisão homologatória de acordo firmado na Ação Civil Pública no 0106890-28.2015.4.01.3700, ser acompanhado de Termo de Consentimento Esclarecido - TCE, que constará de página única, reservada exclusivamente para tal documento, constituindo-se instrumento apartado de outros que formalizem a contratação do Cartão de Crédito Consignado, e conterá, necessariamente: 
I - expressão "TERMO DE CONSENTIMENTO ESCLARECIDO DO CARTÃO DE CRÉDITO CONSIGNADO”, inserida na parte superior do documento e com fonte em tamanho quatorze; II - abaixo da expressão referida no inciso I do caput, em fonte com tamanho onze, o texto: "Em cumprimento à sentença judicial proferida nos autos da Ação Civil Pública n ${ }^{\circ}$ 106890-28.2015.4.01.3700, $3^{\text {a }}$ Vara Federal da Seção Judiciária de São Luís/MA, proposta pela Defensoria Pública da União";

III - nome completo, CPF e número do beneficio do cliente;

IV - logomarca da instituição financeira;

VI - necessariamente como última informação do documento, espaço para preenchimento de local, data e assinatura do cliente;

VII - as seguintes inscrições, todas registradas em fonte com tamanho doze e na ordem aqui apresentada:

a) Contratei um Cartão de Crédito Consignado;

b) Fui informado que a realização de saque mediante a utilização do meu limite do Cartão de Crédito Consignado ensejará a incidência de encargos e que o valor do saque, acrescido destes encargos, constará na minha próxima fatura do cartão;

c) A diferença entre o valor pago mediante consignação (desconto realizado diretamente na remuneração/benefício) e o total da fatura poderá ser paga por meio da minha fatura mensal, o que é recomendado pelo (nome da instituição financeira), já que, caso a fatura não seja integralmente paga até a data de vencimento, incidirão encargos sobre o valor devido, conforme previsto na fatura;

d) Declaro ainda saber que existem outras modalidades de crédito, a exemplo do empréstimo consignado, que possuem juros mensais em percentuais menores;

e) Estou ciente de que a taxa de juros do cartão de crédito consignado é inferior à taxa de juros do cartão de crédito convencional;

f) Sendo utilizado o limite parcial ou total de meu cartão de crédito, para saques ou compras, em uma única transação, o saldo devedor do cartão será liquidado ao final de até (número de meses), contados a partir da data do primeiro desconto em folha, desde que:

1. eu não realize outras transações de qualquer natureza, durante todo o período de amortização projetado a partir da última utilização;

2. não ocorra a redução/perda da minha margem consignável de cartão;

3. os descontos através da consignação ocorram mensalmente, sem interrupção até o total da dívida; 
4. eu não realize qualquer pagamento espontâneo via fatura; e

5. não haja alteração da taxa dos juros remuneratórios;

g) Para tirar dúvidas acerca do contrato ora firmado, inclusive sobre informações presentes neste Termo de Consentimento, o cliente poderá entrar em contato gratuitamente com o (nome da instituição financeira) através do Serviço de Atendimento ao Consumidor SAC (identificar número telefônico) e de sua Ouvidoria (identificar número telefônico) (BRASIL, 2008).

Como se vê, exige-se termo com inúmeros detalhes especificamente declarados no documento, merecendo destaque a alínea "d" do inciso VII do art. 21-A, que prevê a inserção de frase atinente à ciência de que existem outras modalidades de crédito em que incidem juros menores (como o anteriormente indicado empréstimo consignado). Tais especificações, que explicam o pacto em suas minúcias, são absolutamente suficientes para que a instituição financeira cumpra o dever legal de informação.

No tocante à abusividade, a tese é a de que, justamente por existirem outras modalidades negociais em que os juros do empréstimo são menores, estaria a instituição financeira atuando em descompasso com os deveres legais, ao deixar de oferecer ao cliente a opção que lhe é mais vantajosa.

Nesse tópico, há que se anotar que o contrato de RMC não é idêntico ao de empréstimo consignado; embora em ambas o banco disponibilize valor ao devedor, somente neste a instituição tem garantia do pagamento do valor integral. Lado outro, naquele, a garantia é relativa somente ao valor mínimo mensal, de modo que incumbe ao consumidor efetuar o pagamento do valor restante, que consta na fatura. Tal fato, aliado à existência da concessão do cartão de crédito, justifica a incidência de juros maiores no contrato de RMC - que, mesmo assim, costumam ser menores que os juros afetos aos cartões de crédito convencionais.

Demais disso, há casos em que o consumidor já tem comprometida a parcela disponível de sua renda para empréstimo consignado (30\%), mas a lei ainda lhe disponibiliza outra porcentagem para ajuste quanto à RMC (5\%). Nessa hipótese, a tese é derruída de modo ainda mais 
contundente, já que (a) a lei veda a realização de empréstimo consignado, pois o limite máximo já foi atingido; (b) ao mesmo tempo, a lei permite a contratação de RMC; (c) os pactos livremente efetuados pelas partes, em obediência ao sistema normativo vigente, devem ser cumpridos (pacta sunt servanda). Em arremate, o termo de consentimento esclarecido supracitado serve também para esclarecer ao consumidor essa circunstância, isto é, existência de juros menores em outros tipos de empréstimo, como exposto anteriormente.

Também por razão já mencionada - expressa previsão legal -, entende-se inviável o argumento de que ocorre venda casada. Fosse o caso, estar-se-ia entendendo que uma lei (Código de Defesa do Consumidor) é superior a outra (Lei n. 10.820/2003). Ocorre que ambas estão em idêntico patamar, inexistindo, entre ambas, superioridade hierárquica. Além disso, inviável também o uso do critério cronológico para se considerar aplicação do CDC em detrimento da Lei n. 10.820/2003, já que a segunda é posterior. Na verdade, não há conflito normativo, mas mero conflito aparente, por uma razão mui singela: é impossível interpretar que um determinado negócio jurídico é ilegal, se há lei especial que expressamente o admita e regulamenta. A única forma de afastá-lo seria declarar a inconstitucionalidade dos dispositivos da Lei n. 10.820/2003, ponto que sequer costuma ser agitado.

Em suma, se o negócio jurídico firmado não se revelou vantajoso à parte autora, gerando arrependimento posterior ao uso dos recursos financiados, trata-se, tão somente, de questão inerente ao mercado de consumo, não havendo como atribuir ao banco seu descontentamento em relação aos termos da avença celebrada - desde que, por óbvio, tenham sido rigorosamente obedecidos os ditames das outrora indicadas normativas de regência.

\section{RMC NOS JULGADOS DAS TURMAS RECURSAIS DE SANTA CATARINA}

No âmbito das Turmas Recursais catarinenses, o tema em liça foi submetido à Turma de Uniformização dos Recursos Cíveis e Criminais 
e Fazenda Pública do TJSC, tendo sido firmado o entendimento de que a contratação de cartão de crédito consignado com autorização para desconto em benefício previdenciário é válida, desde que obedecidos os requisitos legalmente exigidos e de que inexiste dano moral presumível em caso de sua inobservância. Cita-se a íntegra da elucidativa ementa, que transcreve, ao final, os enunciados resultantes do julgamento:

PEDIDO DE UNIFORMIZAÇÃO DE INTERPRETAÇÃO DE LEI. AÇÃO DE RESTITUIÇÃO DE VALORES C/C INDENIZAÇÃO POR DANO MORAL. RMC - RESERVA DE MARGEM CONSIGNÁVEL. EMPRÉSTIMO POR MEIO DE SAQUE VIA CARTÃO DE CRÉDITO. PRETENSÃO DE DECLARAÇÃO DE INEXISTÊNCIA DA CONTRATAÇÃO DO EMPRÉSTIMO VIA CARTÃO DE CRÉDITO COM RESERVA DE MARGEM CONSIGNÁVEL, RESTITUIÇÃO EM DOBRO DOS DESCONTOS REALIZADOS E INDENIZAÇÃO POR DANOS MORAIS. SENTENÇA DE PROCEDENNCIA NA ORIGEM. RECURSO DA PARTE REQUERIDA. ACÓRDÃO PROVIDO EM PARTE PARA EXCLUSÃO DA RESTITUIÇÃO EM DOBRO E DANOS MORAIS. PREVISÃO LEGAL E REGULAMENTAR DA RMC. MEDIDA PROVISÓRIA 681/2015, CONVERTIDA NA LEI N. 13.172/2015 ALTERANDO DISPOSITIVOS DA LEI 10.820/2003. CONTRATAÇÃO QUE VEIO A SER COMPROVADA PELA INSTITUIÇÃO FINANCEIRA. VALORES LIBERADOS EM FAVOR DAS PARTES CONTRATANTES, ESTAS QUE ADERIRAM LIVRE E CONSCIENTEMENTE AOS CONTRATOS DE EMPRÉSTIMO CONSIGNADO, POR MEIO DE SAQUES VIA CARTÃO DE CRÉDITO. VALIDADE AMPARADA POR LEGISLAÇÃO E REGULAMENTAÇÃO ESPECÍFICA. IMPOSSIBILIDADE DE SE AVENTAR ILEGALIDADES NAS CONTRATAÇÕES. INEXISTÊNCIA DE IMPUGNAÇÕES DAS ASSINATURAS E, TAMBÉM, DE VÍCIOS A MACULAREM AS MANIFESTAÇÕES DE VONTADES EXTERNADAS NA ACEITAÇÃO DOS TERMOS DOS CONTRATOS. INEXISTÊNCIA DE NULIDADES. POR CONSEQUÊNCIA, NÃO CABE TAMBÉM A CONVERSÃO DO CONTRATO EM EMPRÉSTIMO CONSIGNADO, VEZ QUE TAL MODALIDADE DE CRÉDITO ESTÁ AMPARADA EM LEI. INVIÁVEL, NO MAIS, READEQUAÇÃO DOS TERMOS DOS CONTRATOS, POSTO QUE AS INSTITUIÇÕES FINANCEIRAS NÃO INCORRERAM EM QUALQUER PRÁTICA QUE CA- 
RACTERIZE VANTAGEM EXCESSIVA OU ABUSIVA, CAPAZ DE SUBMETEREM OS CONSUMIDORES A SITUAÇÃO DE DESVANTAGEM EXAGERADA OU DE ENCERRAR ILEGALIDADE. POR VIA DE CONSEQUÊNCIA, INEXISTE ABALO ANÍMICO INDENIZÁVEL. DIVERGÊNCIA RECONHECIDA - INTERPRETAÇÃO UNIFORMIZADA PARA ATESTAR A LEGALIDADE DOS CONTRATOS DE CRÉDITO CONSIGNADO COM RESERVA DE MARGEM CONSIGNÁVEL - RMC. DANO MORAL INEXISTENTE. EDIÇÃO DE ENUNCIADOS PARA ORIENTAÇÃO DO SISTEMA DOS JUIZADOS ESPECIAIS, NA FORMA DO ART.66J, §4 $4^{\circ}$ DO REGIMENTO INTERNO DAS TURMAS DE RECURSOS DO SISTEMA DOS JUIZADOS ESPECIAIS DO ESTADO DE SANTA CATARINA COM AS SEGUINTES REDAÇÕES: "XIII - O Juizado Especial é competente para discussão dos contratos que tratam da reserva de margem consignável na Lei n.10.820/2003." "XIV - Observados os termos da Lei n.10.820/03 a da Instrução Normativa n.28/ 2008-INSS, é válido o contrato de cartão de crédito consignado com autorização para desconto em benefício previdenciário, não havendo dano moral presumível no caso de sua contratação com inobservância daquelas regras." (TJSC, Pedido de Uniformização de Interpretação de Lei n. 0000027-49.2018.8.24.9009, de Sexta Turma de Recursos - Lages, rel. Des. Edison Zimmer, Turma de Uniformização, j. 21/10/2018, grifo nosso).

Como pontos de destaque, colhe-se do julgado acima: (a) a validade do contrato de RMC, desde que obedecidas as normativas aplicáveis à espécie e se inexistentes vícios no pacto, do que decorre (b) a impossibilidade de convolar o negócio em empréstimo consignado e (c) a inexistência de dano moral, além de ser assentada (d) a competência do Juizado Especial para julgamento de causas afetas a tal objeto, quando o autor opta pela tramitação pelo rito sumaríssimo. Desse modo, em suma, o entendimento consolidado no âmbito das Turmas Recursais é pelo reconhecimento da validade da contratação da RMC, quando ausente prova do vício e se obedecidos os pressupostos legais aplicáveis à espécie.

Por outro lado, verificam-se em seus julgados casos em que o banco, ao responder à ação, não exibiu o instrumento contratual respectivo, 
mesmo tendo afirmado sua existência. Tem-se entendido, então, que não comprovou o banco suas alegações no sentido de que houve regular pactuação entre as partes, não se desincumbindo do ônus que a lei processual civil the atribui (art. 373, II, CPC). Nessas hipóteses, a maioria dos julgados condena a instituição financeira ao pagamento de danos morais e determina repetição em dobro do valor do financiamento (seguindo nesse sentido, exemplificativamente: Recurso Inominado n. 0308863-31.2017.8.24.0033, de Itajaí, rel. Marco Aurélio Ghisi Machado, Segunda Turma Recursal, j. 27-10-2020; Recurso Inominado n. 0324202-83.2015.8.24.0038, de Joinville, rel. Alexandre Morais da Rosa, Terceira Turma Recursal, j. 23-09-2020; Recurso Inominado n. 0311566-02.2018.8.24.0064, de São José, rel. Antonio Augusto Baggio e Ubaldo, Terceira Turma Recursal, j. 16-09-2020), havendo, ao que se pesquisou, poucos julgados que, ante tal panorama, negam a indenização pelo abalo moral e determinam repetição na forma simples (como é o caso do Recurso Inominado n. 0300632-66.2017.8.24.0113, de Camboriú, rel. Ana Karina Arruda Anzanello, Segunda Turma Recursal, j. 27-10-2020).

Além disso, em pesquisa aos julgados das Turmas Recursais, vê-se que foram inadmitidos pedidos de uniformização de interpretação de lei ante a existência de situações fáticas distintas (por exemplo: Pedido de Uniformização de Interpretação de Lei n. 0000007-53.2021.8.24.9009, de Turmas Recursais, rel. Vitoraldo Bridi, Turma de Uniformização, j. 08-03-2021; Pedido de Uniformização de Interpretação de Lei n. 0000057-16.2020.8.24.9009, de Itajaí, rel. Vitoraldo Bridi, Turma de Uniformização, j. 08-03-2021; Pedido de Uniformização de Interpretação de Lei n. 0000016-49.2020.8.24.9009, de Itajaí, rel. Vitoraldo Bridi, Turma de Uniformização, j. 09-10-2020) - pontuando-se, então, que a ocorrência de danos morais ou do dever de restituição em dobro são aspectos que exigem análise casuística, com base na apreciação da prova, o que impede a concessão da uniformização pretendida. 


\section{RMC NOS JULGADOS DO TRIBUNAL DE JUSTIÇA DE SANTA CATARINA}

Na seara do Tribunal de Justiça catarinense, o entendimento majoritário é em sentido diverso do externado pelas Turmas Recursais, posicionando-se a corrente majoritária pela irregularidade da contratação da reserva de margem consignável por abusividade quanto aos direitos do consumidor.

Mister ressaltar que a Corte inadmitiu dois incidentes de resolução de demandas repetitivas (IRDR) a respeito da temática: o primeiro (Incidente de Resolução de Demandas Repetitivas n. 000071827.2018.8.24.0000, da Capital, rel. Rejane Andersen, Grupo de Câmaras de Direito Comercial, j. 08-08-2018) buscava pacificar o entendimento sobre a (in)existência de dano moral em contratações de cartão de crédito com margem consignável, enquanto o segundo (Incidente de Resolução de Demandas Repetitivas n. 0000507-54.2019.8.24.0000, da Capital, rel. Monteiro Rocha, Grupo de Câmaras de Direito Comercial, j. 12-06-2019) tinha por tema a própria (in)validade da contratação de cartão de crédito com margem consignável. Em ambos os casos, ponderou-se que as questões controvertidas orbitam sobre juízo de valor a respeito da matéria fática, e não apenas da matéria jurídica, o que, conforme se decidiu, inviabiliza o uso do IRDR, pelo desatendimento ao requisito insculpido no art. 976, I, do CPC.

Via de consequência, inexiste, no Tribunal catarinense, julgado de caráter vinculante (art. 927, CPC) sobre a validade ou não da RMC. De toda sorte, o que se percebe, em consulta à jurisprudência da Corte, é que a maioria dos julgados perfilha corrente pela qual referida contratação é abusiva - consignando expressiva parte dos julgados que ao consumidor seria mais benéfica a contratação de empréstimo consignado (principalmente em razão dos juros menores, além de ser certa a duração no tempo), e que a instituição financeira tinha o dever de expor o fato ao cliente, de modo adequado e claro, dever este que se entende não demonstrado pela instituição financeira. 
Ainda, profusa quantidade das decisões reconhece ocorrência de dano moral, inclusive in reipsa; quanto à repetição dos valores, há divergência sobre a forma - havendo decisões pela repetição simples (caso da Apelação n. 5001137-42.2021.8.24.0004, do Tribunal de Justiça de Santa Catarina, rel. Rodolfo Tridapalli, Quinta Câmara de Direito Comercial, j. 10-06-2021) ou pela repetição em dobro (hipótese da Apelação n. 5003779-59.2020.8.24.0024, do Tribunal de Justiça de Santa Catarina, rel. Tulio Pinheiro, Terceira Câmara de Direito Comercial, j. 27-05-2021), com fundamento no parágrafo único do art. 42 do Código de Defesa do Consumidor.

Há, ainda, situações em que, como forma de preservar a existência em si da pactuação, a RMC foi convertida em empréstimo consignado (nesse sentido: Apelação n. 5000031-48.2021.8.24.0003, do Tribunal de Justiça de Santa Catarina, rel. Rodolfo Tridapalli, Quinta Câmara de Direito Comercial, j. 10-06-2021), igualmente porque considerado negócio mais vantajoso ao consumidor, e por se decidir, ainda, que essa era a espécie contratual à qual ele realmente tencionava aderir.

De outra mão, existem também decisões considerando improcedentes (nessa linha: TJSC, Apelação Cível n. 0301424-39.2017.8.24.0042, de Anchieta, rel. Des. Guilherme Nunes Born, Primeira Câmara de Direito Comercial, j. 18/7/2019) os pedidos do consumidor, quando este, ao tempo da contratação, não poderia ter celebrado empréstimo consignado, ante a prévia existência de outros contratos deste jaez e pela impossibilidade de ser excedido o limite de $30 \%$ da renda (v. item 3 supra), o que demonstra, segundo a tese, a certeza de que o consumidor tinha plena ciência da espécie contratual a qual estava, então, aderindo.

Outra circunstância determinante para um resultado pela rejeição dos pedidos do consumidor é a efetiva utilização do cartão de crédito (plástico), o que revelaria, assim, a concreta intenção deste de aderir à específica modalidade contratual - cartão de crédito com reserva de margem consignável -, a afastar, desse modo, as teses de vício na declaração de vontade (como exemplo: TJSC, Apelação n. 500750246.2020.8.24.0005, do Tribunal de Justiça de Santa Catarina, rel. Sérgio Izidoro Heil, Quarta Câmara de Direito Comercial, j. 08-06-2021). 
Alfim, há ainda, em menor número, julgados que peremptoriamente rejeitam a tese do consumidor, reconhecendo a higidez do pacto, quando obedecidos os requisitos legais a respeito (como pode se ver do seguinte julgado: Apelação n. 0300857-60.2019.8.24.0002, do Tribunal de Justiça de Santa Catarina, rel. Luiz Zanelato, Primeira Câmara de Direito Comercial, j. 10-06-2021).

$\mathrm{O}$ estado atual da maioria da jurisprudência da Corte Barriga-Verde, contudo, como exposto supra, continua sendo pelo reconhecimento da abusividade, inclusive condenando-se o banco ao pagamento de indenização por dano moral e repetição em dobro do valor do financiamento. Inobstante, verifica-se um número crescente de julgados em sentido oposto, ou seja, pela manutenção do pacto contratual objeto do presente texto, utilizando-se de fatores como o prévio uso do limite de $30 \%$ do rendimento (que impossibilita novo empréstimo consignado, mas permite apenas contratação de via RMC para uso de mais 5\%) ou a efetiva utilização do cartão de crédito pelo consumidor após a contratação ou ainda a simples observância dos requisitos legais e regulamentares. Tais circunstâncias fundamentam, como visto anteriormente, decisões que reconhecem a higidez da contratação de RMC, o que pode ser um indicativo de possível guinada na jurisprudência.

\section{CONCLUSÃO}

O contrato de cartão de crédito com reserva de margem consignável é, indubitavelmente, uma prodigiosa fonte de onde emanam ações judiciais: em consulta à jurisprudência realizada via site do Tribunal catarinense no dia 10 de junho de 2021, com o termo de pesquisa "reserva de margem consignável", há o retorno do expressivo número de 21.456 resultados, dos quais são 3.553 no âmbito dos Juizados Especiais e 17.903 na seara do Tribunal de Justiça. E isso apenas em segundo grau.

Destaca-se que o primeiro julgado encontrado conforme a pesquisa supracitada, em ordem cronológica, é do final de 2011 - ou seja, o tema ainda sequer completou a primeira década na jurisprudência catarinense. Tal fato demonstra uma litigiosidade extremamente expressiva 
quanto à matéria, ainda mais quando se considera que todas essas ações judiciais são relativas a apenas uma das várias espécies de contratos bancários existentes em nosso país.

A existência de mais ações no Tribunal e menos ações nos Juizados Especiais é de fácil explicação: no Juizado Especial, a parte sabe de antemão que existe entendimento consolidado (o supratranscrito Enunciado XIV), que reza, se obedecidos os requisitos legais, pela regularidade da contratação - enquanto, no Tribunal, o entendimento majoritário é pelo reconhecimento da abusividade. Demais disso, no Juizado não há honorários em primeiro grau, a teor do art. 55 da Lei n. 9.099/1995. Tais fatores, aliado à relativa facilidade de concessão de gratuidade da justiça (uma vez que a maioria das pessoas que busca empréstimo via RMC não possui ganhos financeiros muito expressivos e, com isso, quase invariavelmente obtém justiça gratuita), conduzem a um número de ações pelo rito comum muito maior que pelo rito sumaríssimo do Juizado Especial.

À guisa de conclusão, da parte deste autor, e ressalvados respeitáveis entendimentos em sentido contrário, tem-se imensa dificuldade em enxergar abusividade na contratação de RMC, por um motivo deveras singelo: o contrato conta com expressa previsão legal. Como exposto alhures, a lei e o regulamento não apenas preveem o negócio, mas também o detalham, em suas minúcias e pormenores, exigindo, inclusive, para afastar qualquer dúvida quanto à intenção e ciência do contratante, não apenas o instrumento do contrato, mas também um termo de consentimento esclarecido (art. 21-A, Instrução Normativa INSS n. 28/2008).

Nessa tessitura, na existência do contrato e do termo regularmente assinado pelo consumidor, somente há, entende-se, duas formas ${ }^{2}$ de afastar os termos pactuados: (a) existência de efetiva prova de vício na

2. Uma terceira via para se desconsiderar a lei posta, em tese, seria pensar a pontual possibilidade de derrotabilidade (defeasibility) da regra jurídica, conforme teoria preconizada por Herbert Hart. Contudo, a altíssima frequência dos casos impede, de forma absoluta, o uso da teoria - cuja excepcionalidade, conforme Ávila (2018, p. 139-146), é um dos requisitos. 
declaração de vontade (como, v.g., erro ou dolo); ou (b) reconhecimento de inconstitucionalidade da lei vigente que rege a matéria.

Quanto à primeira hipótese (prova do vício), defende-se que deve se tratar de prova concreta, a ser produzida pelo consumidor, já que impossível de ser presumida tão somente pela idade do consumidor, ou mesmo pela inversão do ônus da prova em desfavor da instituição financeira, pela impossibilidade de ser produzida - ou seja, seria para o banco uma prova diabólica.

Frise-se, por oportuno, quanto às condições pessoais do consumidor, particularmente sua idade, que "o fato de ser idoso não transforma o consumidor em alguém incapaz de compreender e se responsabilizar pelas obrigações que assume decorrentes dos negócios jurídicos por ele firmados" (TJSC, Apelação n. 0300857-60.2019.8.24.0002, do Tribunal de Justiça de Santa Catarina, rel. Luiz Zanelato, Primeira Câmara de Direito Comercial, j. 10-06-2021), sendo descabida, portanto, interpretação que automaticamente conduza o idoso à incapacidade de contratar, sem profunda análise das circunstâncias do caso concreto.

Acerca do ponto em questão, já decidiu o Superior Tribunal de Justiça que pressupor que os idosos possuem capacidade cognitiva e discernimento menores que a população em geral é entendimento que, “[...] a pretexto de realizar os fins protetivos colimados pela Lei $n^{\circ} 10.741 / 2003$ (Estatuto do Idoso) e também pela Lei no 8.078/1990 (CDC), acabou por dispensar tratamento discriminatório indevido a essa parcela útil e produtiva da população. 8. Idoso não é sinônimo de tolo" (STJ, REsp 1.358.057/PR, Rel. Ministro Moura Ribeiro, Terceira Turma, julgado em 22/05/2018, DJe 25/06/2018).

Já no que pertine à segunda hipótese anteriormente aventada (inconstitucionalidade), compreende-se simplesmente não ser o caso, ante a ausência de norma constitucional efetivamente vulnerada pela anteriormente citada legislação.

Sem isso, interpretação que indiscriminada e automaticamente reconhece a invalidade da espécie contratual, divorciada da análise dos meandros do caso concreto, torna a lei em letra morta e, consequente- 
mente, vulnera a segurança jurídica que se espera garantida por meio da liberdade de contratar.

Por tais razões, entende-se pela validade da contratação de reserva de margem consignável, desde que ausente concreta prova de vício na declaração de vontade do contratante e, ainda, se obedecidos os requisitos pormenorizadamente previstos na lei específica e no regulamento da matéria.

\section{REFERÊNCIAS}

ÁVILA, Humberto. Teoria dos princípios: da definição à aplicação dos princípios jurídicos. 18. ed. São Paulo: Malheiros, 2018.

\section{BRASIL. Constituição da República Federativa do Brasil (1988).} Disponível em: www.planalto.gov.br/ccivil_03/constituicao/constituicao.htm. Acesso em: 2 jun. 2021.

BRASIL. Lei n. 10.406 (2002). Código civil. Disponível em: www. planalto.gov.br/ccivil_03/leis/2002/110406compilada.htm. Acesso em: 2 jun. 2021.

BRASIL. Lei n. 10.820 (2003). Disponível em: www.planalto.gov.br/ ccivil_03/leis/2003/L10.820Compilado.htm. Acesso em: 2 jun. 2021.

BRASIL. Lei n. 14.131 (2021). Disponível em: www.planalto.gov. br/ccivil_03/_ato2019-2022/2021/lei/L14131.htm. Acesso em: 2 jun. 2021.

BRASIL. Lei n. 8.078 (1990). Código de defesa do consumidor. Disponível em: www.planalto.gov.br/ccivil_03/leis/18078.htm. Acesso em: 2 jun. 2021.

BRASIL. Instituto Nacional do Seguro Social. Instrução normativa INSS n. 14 (2021). Diário Oficial da União (DOU) n. 75, de 23 de abril de 2021, Seção 1, p. 109. Disponível em: https://pesquisa.in.gov.br/ imprensa/jsp/visualiza/index.jsp?data $=23 / 04 / 2021 \&$ jornal $=515 \&$ pagina=109\&totalArquivos=208. Acesso em: 2 jun. 2021. 
BRASIL. Instituto Nacional do Seguro Social. Instrução normativa INSS n. 28 (2008). Diário Oficial da União (DOU) n. 94, de 19 de maio de 2008, Seção 1, p. 102-104. Disponível em: pesquisa.in.gov. br/imprensa/jsp/visualiza/index.jsp?data=19/05/2008\&jornal=1\&pagina $=102 \&$ totalArquivos=140. Acesso em: 2 jun. 2021.

BRASIL. Ministério da Economia. Exposição de motivos n. 00359/2020 ME (2020). Disponível em: www.planalto.gov.br/ccivil_03/_Ato20192022/2020/Exm/Exm-MP-1006-20.pdf. Acesso em: 2 jun. 2021.

BRASIL. Superior Tribunal de Justiça. Recurso Especial n. 106.888/ PR. Rel. Min. Cesar Asfor Rocha, Segunda Seção, j. 28-3-2021, DJ 5-8-2002.

BRASIL. Superior Tribunal de Justiça. Recurso Especial n.1.358.057/ PR. Rel. Min. Moura Ribeiro, Terceira Turma, j. 22-5-2018, DJe 25-62018.

BRASIL. Superior Tribunal de Justiça. Súmula n. 297. O Código de Defesa do Consumidor é aplicável às instituições financeiras. Disponível em: www.stj.jus.br/docs_internet/revista/eletronica/stj-revista-sumulas-2011_23_capSumula297.pdf. Acesso em: 2 jun. 2021.

GONÇALVES, Carlos Roberto. Direito civil brasileiro: parte geral. 16. ed. São Paulo: Saraiva Educação, 2018, p. 414-415.

POMODORO, Julia Ceglias. A violação do dever de informação nos contratos de concessão de crédito e o superendividamento do consumidor. Trabalho de Conclusão de Curso (Bacharelado em Direito) - Faculdade de Direito de Vitoria, Vitória, 2019. Disponível em: 191.252.194.60:8080/handle/fdv/785. Acesso em: 2 jun. 2021.

PRAZERES, Paulo Joviano dos; PRAZERES, Karla Luzia Alvares dos. Trajetória histórica e crítica das teorias de vinculação dos direitos fundamentais no Estado Democrático de Direito e as teorias da eficácia dos direitos humanos. Revista Reflexão e Crítica do Direito, v. 7. n. 2, p. 224-243, jul./dez. 2019. Disponível em: revistas.unaerp.br/rcd/article/download/1937/1516. Acesso em: 2 jun. 2021. 
SANTA CATARINA. Tribunal de Justiça. Apelação Cível n. 001692987.2011.8.24.0064, de São José. Rel. Des. Fernando Carioni, Terceira Câmara de Direito Civil, j. 5-11-2019.

SANTA CATARINA. Tribunal de Justiça. Apelação n. 030085760.2019.8.24.0002, de Anchieta. Rel. Des. Luiz Zanelato, Primeira Câmara de Direito Comercial, j. 10-06-2021.

SANTA CATARINA. Tribunal de Justiça. Incidente de Resolução de Demandas Repetitivas n. 0000507-54.2019.8.24.0000, da Capital. Rel. Des. Monteiro Rocha, Grupo de Câmaras de Direito Comercial, j. 12-06-2019.

SANTA CATARINA. Turma de Uniformização. Pedido de Uniformização de Interpretação de Lei n. 0000027-49.2018.8.24.9009, de Lages. Rel. Juiz Edison Zimmer, j. 22-10-2018.

TARTUCE, Flavio. Manual de direito civil. 10. ed. São Paulo: Método, 2020, n.p. 